\title{
1
}

\section{Digital Dilemmas in Organizations}

\begin{abstract}
Social media platforms are at the core of the digital transformation of organizations. This chapter outlines the current study's threefold purpose, which is to (1) categorize ethical dilemmas that can occur for professionals who run social media platforms for their organizations, (2) propose conceptual tools for reflecting on those dilemmas and (3) outline how social media ethics affects leadership in organizations. Social media enables individuals, groups and organizations to publish content without going through an editor, so it facilitates quick exchanges with a range of stakeholders. The current study is the first to map and categorize the ethical dilemmas that can occur in organizations that use social media. Input for the study comes from executive students at a European business school. The study's overall aim is to provide a platform for systematic and reflective handling of ethical dilemmas for practitioners who are responsible for social media accounts at their organizations.
\end{abstract}

Keywords Ethical dilemmas $\bullet$ Social media $\bullet$ Organizational ethics $\bullet$ Facebook • Leadership 
Anne is a communications advisor for a construction company. One of her tasks is to run a Facebook account dedicated to a construction project in the mountains, where the company is building a large tunnel. The construction manager is a good photographer, and he frequently submits photos from the project for publication on Facebook. People can follow the progress and milestones of the tunnel construction through its Facebook account. This creates pride in and excitement about the project, and the employees are energized by such frequent public displays of their achievements. One day, Anne receives a new set of photos from the construction manager and immediately posts them on Facebook. This time, one photo happens to document a serious health, safety and environment (HSE) violation by one of the employees. The purpose of posting the photo was to document normal activity at the project, but it shows a worker in action without a helmet. The company has recently had serious accidents at the project site due to a lack of helmet use. Angry users have already noted the violation and commented about it on Facebook. How should Anne cope with the situation? Either she can respond to the criticism and risk bringing even more attention to the HSE violation, or she can delete the photo and hope that there will be no further criticism. No matter what she decides to do, there is a risk of subsequent problems.

Social media platforms are at the core of digital transformations in organizations. They introduce a range of new ways for individuals, groups and organizations to spread, share and comment on ideas, beliefs and information (Kane, 2017; Kaplan \& Haenlein, 2010). People no longer need to go through an editor to publish their opinions or photos to a wide audience. Exchanges happen quickly, creating a sense of always being current and up to date. This fast tempo also increases the risk of mistakes, as in the example involving Anne and the publication of a photo documenting an HSE violation. The combination of an increased scope of action and rapid publication creates a range of ethical dilemmas for decision-makers within organizations. Those who are responsible for handling organizations' social media accounts can face situations in which they must prioritize conflicting ethical considerations. No matter what they decide to do, something of ethical value is lost. 
This book is aimed at categorizing the concrete digital dilemmas that occur when organizations use social media platforms to interact with stakeholders. Data were collected from approximately 250 executive students at a European business school over a five-year period. Each student was invited to formulate a personal digital dilemma, a situation at work in which they had to prioritize certain ethical considerations. The students are practitioners responsible for handling social media platforms for their organizations. As such, they have first-hand experience with encountering and addressing ethical challenges related to organizational social media use.

The book has a threefold purpose. First, it sets out to categorize ethical dilemmas that arise for people who handle social media platforms for organizations across industries, disciplines and professions. No previous studies have aimed to accomplish this goal. Research on the ethical aspects of social media use tends to be industry and discipline specific. The current study contributes to a much-needed clarification of the concrete dilemmas that arise in workplaces adapting to a reality in which social media platforms have created a radically different environment for conversation and interaction. The author previously outlined this categorization in a book chapter (Kvalnes, 2019), but this book contains the first detailed account.

Second, the book provides a systematic framework for analyzing ethical dilemmas related to social media use. A key component of this framework is the Navigation Wheel developed by Kvalnes and Øverenget (2012). It guides decision-makers through a process of considering questions regarding law (is it legal?), identity (is it in accordance with our corporate or professional values?), morality (is it in line with our convictions and beliefs about right and wrong?), reputation (does it affect our goodwill?), economy (is it profitable?) and ethics (can we justify it using ethical principles and theories?). The Navigation Wheel framework can be used in teaching and learning processes in academic and other organizational settings.

Third, the book addresses how digital dilemmas and ethics on social media have consequences for leadership. Many of this study's informants reported weak or absent support from their leaders when dealing with such dilemmas. In some cases, the leaders even pushed the responsibility 
of responding to ethically questionable uses of social media in the organization onto employees who are social media experts rather than doing it themselves. The book analyzes these tendencies and their possible remedies under the headings of ethical leadership (Brown, Treviño, \& Harrison, 2005) and balanced leadership (Müller, Packendorff, \& Sankaran, 2017).

\section{Ethics on Social Media}

Social media has been defined as "a group of Internet-based applications that build on the ideological and technological foundations of Web 2.0, and allow the creation and exchange of user generated content" (Kaplan \& Haenlein, 2010, p. 61). It can be seen as a diverse and evolving technological infrastructure that supports and changes how people communicate and collaborate (Kane, 2017). Facebook, Twitter, LinkedIn, Snapchat and other social media platforms create a multitude of ways an organization can develop and disseminate its corporate identity (Devereux, Melewar, \& Foroudi, 2017). Inappropriate social media strategies can rapidly create and fuel corporate crises (Ott \& Theunissen, 2015).

Social media creates ethical challenges that go beyond those addressed in traditional media ethics, which positions the professional editor as the prime decision-maker (Kieran, 2002) and concerns itself with the duties of journalists before, during and after publication (Bertrand, 2018; Duffy \& Knight, 2019). Social media enables individuals to be their own publishers, and this creates new and unfamiliar ethical dilemmas for practitioners in the field. This book attempts to identify and address such dilemmas in a systematic manner with the dual ambition of contributing to organizational ethics research and offering a conceptual framework to ease the ethical tension that practitioners experience through the categorization and through the framework for ethical analysis.

The decision-makers in traditional media are journalists and editors, who are responsible for the content they publish. Information that reaches the public through various media shapes people's worldviews, perceptions and attitudes, placing a particularly strong ethical responsibility on the professionals who decide what to publish and how to 
publicize it (Kieran, 2002). Journalists are expected to follow ethical guidelines and principles that reflect their power to influence people's mindsets (Ward, 2005). As professionals, they have a particular responsibility to remain honest and act in the public interest (Iggers, 2018). Digital journalists face a range of complex ethical challenges in relation to misinformation and fake news (Bakir \& McStay, 2018; Lazer et al., 2018; Pennycook \& Rand, 2019).

Users of Facebook, Twitter, Instagram, LinkedIn, Snapchat and other social media platforms are their own publicists. They do not depend on the support of an editor or a journalist to make their content publicly available. Traditional media ethics fail to the range of ethical issues that arise under these radically changed communication conditions. Social media users can play multiple roles and serve multiple purposes that go far beyond those of an editor or a journalist. They, too, may have strong reasons to be concerned about honesty, the public interest and the reliability of information, but their scope of action is wider and less restricted by professional norms, duties and expectations.

The thrills of social media use include the rapid exchange of ideas and the impulsive posting of content. However, this fast tempo also creates ethical problems. The opening example from the construction company illustrates how carefree and immediate social media use creates dilemmas for decision-makers. Two mistakes have already occurred. The first was the employee's HSE violation of working in an unsafe environment without a helmet, and the second was to publish a photo documenting that mistake on Facebook. Now the person responsible for company's social media accounts must determine how to deal with the situation. None of the options available to her is without ethical costs. In the name of transparency and honesty, she can reply to the critic, then remove the photo. In the name of protecting the employee and the organization from further public scrutiny for the mistake, she can remove the photo immediately and proceed with the hope that viewers will move on and make no further comments about it. There are no harmonious options available in which everyone is satisfied with the ethical aspects of the decision. This example is presented and discussed in further detail in Chap. 3 . 


\section{Morality, Ethics and Dilemmas}

Kahneman (2013) distinguished between two modes of decision-making. System 1 is his name for the quick, intuitive mode, whereas System 2 is his label for the slow, analytic mode. This distinction is relevant in the current context of investigating dilemmas related to social media. When challenging situations occur, decision-makers can decide and act intuitively based on gut feelings about what they should do under such circumstances, or they can take time to think through the available options, consider their advantages and disadvantages in light of how they affect different stakeholders and reach a decision.

We can bring the concepts of morality and ethics into play to describe these decision-making processes. Morality can be understood as people's personal and shared beliefs about right and wrong. These beliefs develop over time in social settings because people develop moral standards and convictions through social learning processes. Ethics, on the other hand, can be defined as the academic discipline of thinking systematically about right and wrong (Goodpaster, 1992; Kvalnes, 2019). People can learn ethics from reading books and attending courses and seminars. Ethical principles and theories can guide our reasoning about right and wrong. For example, the Golden Rule is an ethical principle situated in various religious and nonreligious traditions that serves as an action-guiding tool for decision-makers.

With these definitions of morality and ethics in place, we can distinguish between two ways of reaching a decision in a dilemma. The first is to apply moral intuition and quickly determine a course of action (System 1 ), and the second is to slow down and apply ethical theories and principles to the case at hand (System 2). Chapter 3 presents a set of principles that can guide decision-making in social media contexts. The Navigation Wheel is a cognitive tool that provides a framework for analyzing ethical dilemmas. It can also be applied in situations outside that context, so it is not uniquely designed for handling ethical dilemmas on social media.

Egorov, Verdorfer, and Peus (2018) argued against a rationalistic tendency in studies of ethical decision-making in organizations and claimed 
that moral intuition plays an unacknowledged and significant role in those processes. The current exploration of digital dilemmas and ethics in the context of social media does not deny the relevance of quick moral thinking, but is concerned with its limitations. The proposed systematic tools for handling dilemmas supplement moral intuitions rather than downgrade them, so using these tools does not constitute overt rationalism in the sense described by Egorov et al. (2018).

A dilemma can be defined as a situation in which the decision-maker must choose between two or more alternatives that have more or less equal moral weight or ethical value (Kvalnes, 2019; Maclagan, 2003, 2012). No matter what he or she decides to do, one or more important consideration must be prioritized at the expense of another. Thus, whatever the agent decides to do, there will be an element of wrongness to it (Brinkmann, 2005; Kvalnes, 2019; Maclagan, 2003, 2012; Toffler, 1986). It is common to distinguish between dilemmas and temptations (Brinkmann, 2005), or between real and false dilemmas (Kvalnes, 2019; Maclagan, 2003, 2012). The former are situations in which there is a genuine tension between two or more alternatives that have a strong moral or ethical value attached to them, and it is difficult to identify the best alternative. The latter are situations in which it is rather obvious what one should do, from an ethical perspective, but one is tempted, ordered or for other reasons drawn toward the unethical alternative.

Previous studies have focused on industry-specific ethical dilemmas and challenges related to the uses of social media. In medicine, there is an emerging awareness of the ethical implications of social media use that involves sharing stories and pictures of patients (McKlindon et al., 2016; Palacios-González, 2015; Wells, Lehavot, \& Isaac, 2015). Warnick, Bitters, Falk, and Kim (2016) discussed the responsibilities of teachers who interact with their pupils or students on social media, and Fenwick (2016) suggested that responsible use of social media should be an integral element of teaching professionalism to students. An emerging research stream focuses on the use of social media to collect big data for research, product development and marketing. Social media can vastly improve the reach and efficiency of such processes, but the available methods also create considerable ethical dilemmas with regard to privacy 
(Bender, Cyr, Arbuckle, \& Ferris, 2017; Gelinas et al., 2017; Kosinski, Matz, Gosling, Popov, \& Stillwell, 2015; Mittelstadt \& Floridi, 2016).

The novelty of the current study is that it identifies generic ethical dilemmas that can occur across industries and sectors. Such dilemmas can arise in any organization that uses social media to communicate with its stakeholders. The findings and discussion are thus relevant in any organization that uses social media.

\section{Methodology}

Executive students at a European business school provided input for the present categorization of ethical dilemmas. The students participated in a Master of Management program on digitalization and leadership. The program included five 4-day modules and ran from September to May. The students are professionals aged 30 and above in the private and public sectors. They work with the implementation of digital platforms and social media strategies and practices at their own organizations.

In four of the five modules, the students participated in a three-hour ethics session in which they became familiar with ethical concepts and theories and applied them in discussions of concrete cases. The author of this book was their teacher for all modules. In the period between modules 1 and 2 (four to six weeks), the students completed a home assignment titled "My digital dilemma" that consisted of writing up one ethical dilemma connected to their own experiences using social media at work. The data for the current study are derived from the memos the students handed in for this assignment. The data were collected from classes of around 50 students during each study year from 2013-2014 to 2017-2018. Thus, approximately 250 students contributed to the data set through their participation in the assignment.

Dilemmas submitted by the students were also used during teaching sessions, and that process generated new examples that were outlined orally in the classroom by students who were reminded of similar episodes from their own organizations and work environments.

The threefold motivation behind the home assignment of describing a social media dilemma was as follows: 
1. Stimulate the students' ethical self-reflection by encouraging them to explore the connections between ethical concepts and their own work practices.

2. Generate a social media dilemma bank for use when teaching future classes in the same program.

3. Investigate and research what executive students consider the main ethical challenges of social media use in their organizations.

The students consented to the anonymized use of their contributions. Whenever a dilemma was considered for use in a teaching module for which the contributor would be present, that person was asked (1) for permission to use the dilemma in that context and (2) whether he or she wanted to be anonymous or open about being the source of the dilemma. In the latter case, the student could then elaborate on further details and discuss the dilemma with the teacher and fellow students. Whenever a dilemma has been considered for quotation, the student who provided it was given the opportunity to withdraw it or request revisions to ensure anonymization. No students chose to withdraw their contribution, but one asked for further anonymization before accepting the inclusion of her dilemma in this book.

The assignment proceeded from the dilemma definition provided above but highlighted that students needed not describe a dilemma in its strictest form. Maclagan (2003) noted that actual dilemma cases tend to occur on a spectrum between what people perceive as real and false dilemmas. On one side of the scale are real dilemmas in their purest form, in which people perceive the ethical weight of both alternatives as equal. On the other side of the scale are false dilemmas, in which one option is clearly ethically optimal, while the other is obviously unethical, but the decision-maker is nevertheless drawn to the unethical choice because he or she is tempted or under pressure to perform it. Most cases in the material used in this study are not so clear. In addition, people disagree about the ethical weight of the available alternatives and, therefore, the extent to which they are real or false dilemmas. However, all the cases are ethically challenging because they test the decision-maker's ability to weigh ethical values and other considerations against each other. 
The dilemma outlined at the beginning of this chapter belongs to the side of the scale closest to that of the false dilemmas. It might be tempting to remove the photo and hope that the publicized HSE violation goes more or less unnoticed and that the critic calms down, but from an ethical perspective, the organization should most likely acknowledge the mistake and publish a reply to the critic before removing the photo. The employee who made the mistake might prefer the option to immediately remove the photo, but the ethical weight of shielding him and the organization from further public scrutiny and criticism is less than that of being transparent and open about the mistake.

The opening dilemma was described in a memo written by one of the student informants. The material overall is multifaceted and rich, and it illustrates the ethical challenges and confusion that can arise with the emergence of new technology. The students signaled that it is difficult to cope with these situations at work because of the following:

1. Insufficient support from leaders, who tend to have a restricted understanding of how social media works

2. A lack of established codes or norms

3. An absence of narratives about exemplary handlings of previous cases

4. Limited access to concepts and ideas that clarify the issues at stake

Initial meetings with these students highlighted a need for research to elucidate the ethical challenges they encounter at work. The current book sets out to provide this by providing a systematic account of the ethical dilemmas that can arise for employees who handle social media accounts in organizational contexts across disciplines and industries. Leaders should also be aware of these dilemmas so they can adequately support their employees.

The approach is abductive in nature in that categorization and theory gradually develop through the exploration of insights that arise in dialogue with practitioners who work with and within the phenomena described by the theory (Peirce, 1903). Input comes both from student memos and from discussions of memos during teaching sessions. The study is an attempt to engage a phenomenon from the perspective of those living it (Corley, 2015). A methodological assumption borrowed 
from grounded theory is that the executive students who contributed to this study are knowledgeable agents who know what they are trying to do and can explain their thoughts, intentions and actions (Gioia, Corley, \& Hamilton, 2013). The study is an effort to make sense of a complex reality, starting with an invitation to practitioners to share their experiences with ethical dilemmas in their work with social media. The analytical process consisted of (1) interpreting written input from the executive students, (2) discussing their examples with them in the classroom, (3) returning to the informants with suggested categories and (4) rewriting and modifying the categories.

Martela (2015) claimed that the novel theoretical insights that arise from abductive inquiry should be judged according to the practical usability of the proposed views for the particular actors working with and within the phenomena described in the theory. A similar assumption guides the current study, which aims to generate a theory to support and enhance ethically responsible decision-making and behavior in the use of social media by practitioners whose organizational roles resemble those of the students who contributed to the study.

Data collection for this book occurred in a teaching context, so the findings are also relevant for teaching purposes, particularly those aimed at preparing practitioners for ethical challenges at work. With a model for categorizing ethical dilemmas in place, individuals, groups and organizations can prepare for encounters with such dilemmas in their use of social media. Ethical training can be effective in generating responsible decisionmaking and behavior (Kaptein, 2015; Valentine \& Fleischman, 2004). A set of example dilemmas and categories can help to structure the training. Weber (2007) identified inductive learning as a particularly satisfying and productive approach to teaching ethics because it encourages the learner to reflect on concrete examples. This book aims to create a foundation for such learning.

The book is organized as follows: The next chapter presents and discusses the dilemma categories that emerged from the student memos. This is followed by a chapter that presents the Navigation Wheel as a tool for analyzing about ethical dilemmas on social media. The final chapter outlines consequences for leadership in organizations in which social media is at the core of the digital transformation, and it supplies a final 
thought on how ethics on social media encompass considerations about doing good and avoiding harm.

\section{References}

Bakir, V., \& McStay, A. (2018). Fake news and the economy of emotions: Problems, causes, solutions. Digital Journalism, 6(2), 154-175.

Bender, J. L., Cyr, A. B., Arbuckle, L., \& Ferris, L. E. (2017). Ethics and privacy implications of using the internet and social media to recruit participants for health research: A privacy-by-design framework for online recruitment. Journal of Medical Internet Research, 19(4), e104.

Bertrand, C.-J. (2018). Media ethics and accountability systems. London and New York: Routledge.

Brinkmann, J. (2005). Understanding insurance customer dishonesty: Outline of a situational approach. Journal of Business Ethics, 61(2), 183-197.

Brown, M. E., Treviño, L. K., \& Harrison, D. A. (2005). Ethical leadership: A social learning perspective for construct development and testing. Organizational Behavior and Human Decision Processes, 97(2), 117-134.

Corley, K. G. (2015). A commentary on "what grounded theory is ...” engaging a phenomenon from the perspective of those living it. Organizational Research Methods, 18(4), 600-605.

Devereux, L., Melewar, T., \& Foroudi, P. (2017). Corporate identity and social media: Existence and extension of the organization. International Studies of Management \& Organization, 47(2), 110-134.

Duffy, A., \& Knight, M. (2019). Don't be stupid: The role of social media policies in journalistic boundary-setting. Journalism Studies, 20(7), 932-951.

Egorov, M., Verdorfer, A. P., \& Peus, C. (2018). Taming the emotional dog: Moral intuition and ethically-oriented leader development. Journal of Business Ethics, 160(3), 1-18.

Fenwick, T. (2016). Social media, professionalism and higher education: A sociomaterial consideration. Studies in Higher Education, 41(4), 664-677.

Gelinas, L., Pierce, R., Winkler, S., Cohen, I. G., Lynch, H. F., \& Bierer, B. E. (2017). Using social media as a research recruitment tool: Ethical issues and recommendations. The American Journal of Bioethics, 17(3), 3-14.

Gioia, D. A., Corley, K. G., \& Hamilton, A. L. (2013). Seeking qualitative rigor in inductive research: Notes on the Gioia methodology. Organizational Research Methods, 16(1), 15-31. 
Goodpaster, K. E. (1992). Business ethics. In L. C. Becker \& C. B. Becker (Eds.), Encyclopedia of ethics. New York: Garland Publishing.

Iggers, J. (2018). Good news, bad news: Journalism ethics and the public interest. New York and London: Routledge.

Kahneman, D. (2013). Thinking, fast and slow. New York: Farrar, Straus and Giroux.

Kane, G. C. (2017). The evolutionary implications of social media for organizational knowledge management. Information and Organization, 27(1), 37-46. Kaplan, A. M., \& Haenlein, M. (2010). Users of the world, unite! The challenges and opportunities of social media. Business Horizons, 53(1), 59-68.

Kaptein, M. (2015). The effectiveness of ethics programs: The role of scope, composition, and sequence. Journal of Business Ethics, 132(2), 415-431.

Kieran, M. (2002). Media ethics. London: Routledge.

Kosinski, M., Matz, S. C., Gosling, S. D., Popov, V., \& Stillwell, D. (2015). Facebook as a research tool for the social sciences: Opportunities, challenges, ethical considerations, and practical guidelines. American Psychologist, 70(6), 543.

Kvalnes, Ø. (2019). Moral reasoning at work: Rethinking ethics in organizations (2nd ed.). London: Palgrave Macmillan.

Kvalnes, Ø., \& Øverenget, E. (2012). Ethical navigation in leadership training. Etikk i praksis-Nordic Journal of Applied Ethics, 6(1), 58-71.

Lazer, D. M., Baum, M. A., Benkler, Y., Berinsky, A. J., Greenhill, K. M., Menczer, F., ... Rothschild, D. (2018). The science of fake news. Science, 359(6380), 1094-1096.

Maclagan, P. (2003). Varieties of moral issue and dilemma: A framework for the analysis of case material in business ethics education. Journal of Business Ethics, 48(1), 21-32.

Maclagan, P. (2012). Conflicting obligations, moral dilemmas and the development of judgement through business ethics education. Business Ethics: A European Review, 21(2), 183-197.

Martela, F. (2015). Fallible inquiry with ethical ends-in-view: A pragmatist philosophy of science for organizational research. Organization Studies, 36(4), 537-563.

McKlindon, D., Jacobson, J. A., Nathanson, P., Walter, J. K., Lantos, J. D., \& Feudtner, C. (2016). Ethics rounds: In the eye of a social media storm. Pediatrics, 138(3), e20161398. 
Mittelstadt, B. D., \& Floridi, L. (2016). The ethics of big data: Current and foreseeable issues in biomedical contexts. Science and Engineering Ethics, 22(2), 303-341.

Müller, R., Packendorff, J., \& Sankaran, S. (2017). Balanced leadership: A new perspective for leadership in organizational project management. In S. Sankaran, R. Müller, \& N. Drouin (Eds.), Cambridge handbook of organizational project management. Cambridge: Cambridge University Press.

Ott, L., \& Theunissen, P. (2015). Reputations at risk: Engagement during social media crises. Public Relations Review, 41(1), 97-102.

Palacios-González, C. (2015). The ethics of clinical photography and social media. Medicine, Health Care and Philosophy, 18(1), 63-70.

Peirce, C. S. (1903). Pragmatism and the logic of abduction. In The essential Peirce: Selected philosophical writings (Vol. 2, pp. 226-242). Bloomington: Indiana University Press.

Pennycook, G., \& Rand, D. G. (2019). Lazy, not biased: Susceptibility to partisan fake news is better explained by lack of reasoning than by motivated reasoning. Cognition, 188, 39-50.

Toffler, B. L. (1986). Tough choices: Managers talk ethics. New York: Wiley.

Valentine, S., \& Fleischman, G. (2004). Ethics training and businesspersons' perceptions of organizational ethics. Journal of Business Ethics, 52(4), 391-400. Ward, S. J. (2005). Philosophical foundations for global journalism ethics. Journal of Mass Media Ethics, 20(1), 3-21.

Warnick, B. R., Bitters, T. A., Falk, T. M., \& Kim, S. H. (2016). Social media use and teacher ethics. Educational Policy, 30(5), 771-795.

Weber, J. A. (2007). Business ethics training: Insights from learning theory. Journal of Business Ethics, 70(1), 61-85.

Wells, D. M., Lehavot, K., \& Isaac, M. L. (2015). Sounding off on social media: The ethics of patient storytelling in the modern era. Academic Medicine, 90(8), 1015-1019. 
Open Access This chapter is licensed under the terms of the Creative Commons Attribution 4.0 International License (http://creativecommons.org/licenses/ by/4.0/), which permits use, sharing, adaptation, distribution and reproduction in any medium or format, as long as you give appropriate credit to the original author(s) and the source, provide a link to the Creative Commons licence and indicate if changes were made.

The images or other third party material in this chapter are included in the chapter's Creative Commons licence, unless indicated otherwise in a credit line to the material. If material is not included in the chapter's Creative Commons licence and your intended use is not permitted by statutory regulation or exceeds the permitted use, you will need to obtain permission directly from the copyright holder.

(c) (1) 